\title{
Atividade antifúngica do resveratrol em cepas de Candida spp.
}

\author{
Letícia Carolina da Cruz \\ Graduada em Biomedicina pela Universidade Luterana do Brasil - Ulbra \\ Biomédica Responsável Técnica do Laboratório Escola de Biomedicina da Universidade Luterana do Brasil \\ 凶leti.bio@live.com
}

\begin{abstract}
Alexandre Ehrhardt
Orientador do trabalho, Graduado em Farmácia e Bioquímica (UFSM) e em Biomedicina (ULBRA), Pósgraduado em Ciências Farmacêuticas (UFSM) e em Toxicologia Aplicada (PUC-RS). Mestre em Farmacologia e Terapêutica (UFRGS). Docente e orientador de estágio no curso de Biomedicina da Universidade Luterana do Brasil - Campus Carazinho/RS. Perito do Tribunal de Justiça do Rio Grande do Sul na área de Análises Clínicas e

Toxicológicas. Experiência na área de Análises Clínicas e Toxicológicas, com ênfase em Toxicologia

/Farmacologia e Imunologia.

$凶$ bioquimicoalexandre@gmail.com
\end{abstract}

\section{Resumo:}

O resveratrol, encontrado na uva e no vinho, possui ação anti-inflamatória, antifúngica, antioxidante e pode ser comumente utilizado para fins medicinais. Considerando que os fungos como as espécies de Candida spp. se apresentam cada vez mais resistentes aos antifúngicos convencionais, o objetivo deste trabalho foi analisar a ação antifúngica do resveratrol sobre cepas de diferentes espécies de Candida spp. Utilizou-se uma metodologia adaptada na qual culturas de C. albicans, C. glabrata, C. krusei, C. tropicalis e C. parapsilosis, foram testadas frente a 3 diferentes concentrações de resveratrol em pó, e também 3 diferentes marcas de suco de uva integral, utilizando o Fluconazol como controle. Inicialmente dilui-se 0,5 gramas de resveratrol em pó sobre $100 \mathrm{ml}$ de DMSO, a partir desta realizou-se diluições correspondentes a $10^{1}, 10^{2}, 10^{3}$ as quais foram pipetadas em placas de Nest $1,8 \mathrm{ml}$ de cada diluição juntamente com $200 u$ de cada inoculo fúngico. Posteriormente essas amostras foram semeadas em ágar mycosel. A mesma metodologia seguiu na utilização dos sucos de uva. Percebeu-se inibição do crescimento fúngico das cinco espécies testadas demonstrando a atividade do resveratrol contra os isolados de Candida. Porém, o tratamento com a menor porcentagem de resveratrol utilizado no estudo não desencadeou inibição do crescimento das espécies C. glabrata e C. tropicalis. Quanto aos testes com suco, duas das três marcas testadas tiveram a ação semelhante ao do resveratrol em pó sobre as cepas de Candida. Considerando os resultados obtidos, pode-se sugerir a utilização do resveratrol como sendo uma substância antifúngica em potencial.

Palavras-chave: Polifenol, Polygonum cuspidatum, Antifúngicos, Triazóis.

\section{Antifungal activity of resveratrol in strains of Candida spp.}

\begin{abstract}
:
Resveratrol, found in grape and wine, has anti-inflammatory, antifungal, antioxidant action and can be commonly used for medicinal purposes. As the species of Candida spp. The objective of this work
\end{abstract}


was to analyze the antifungal action of resveratrol on strains of different species of Candida spp. A methodology adapted for the cultures of C. albicans, C. glabrata, C. krusei, C. tropicalis and C. parapsilosis, were tested against 3 different concentrations of resveratrol powder, as well as 3 different brands of juice of Intactally dilute 0.5 grams of resveratrol powder in $100 \mathrm{ml}$ of DMSO, under destroyed conditions corresponding to $10^{1}, 10^{2}, 10^{3}$ as they were pipetted into Nest 1 plates, 8 $\mathrm{ml}$ of each dilution With $200 \mathrm{ul}$ of each fungal inoculum. Subsequently these were seeded into mycosel agar. The same methodology is used in grape juice. Inhibition of fungal growth of the five species tested was observed demonstrating a resveratrol activity against the elements of Candida. However, the treatment with lower percentage of resveratrol used did not trigger inhibition of the growth of C. glabrata and C. tropicalis species. There are two successful tests, two of the three brands tested and one action similar to that of resveratrol powder on as strains of Candida. The results obtained may suggest the use of resveratrol as a potential antifungal substance.

Keywords: Polyphenol, Polygonum cuspidatum, Antifungals, Triazoles.

\section{Actividad antifúngica del resveratrol en cepas de Candida spp.}

\section{Resumen:}

El resveratrol, encontrado en la uva y en el vino, tiene acción anti-inflamatoria, antifúngica, antioxidante y puede ser utilizado comúnmente para fines medicinales. Considerando que los hongos como las especies de Candida spp. se presentan cada vez más resistentes a los antifúngicos convencionales, el objetivo de este trabajo fue analizar la acción antifúngica del resveratrol sobre cepas de diferentes especies de Candida spp. Se utilizó una metodología adaptada en la cual se estudiaron cultivos de C. albicans, C. glabrata, C. krusei, C. tropicalis y C. parapsilosis, frente a 3 diferentes concentraciones de resveratrol en polvo, y también 3 diferentes marcas de jugo de uva integral, utilizando el Fluconazol como control. Inicialmente se diluyeron 0,5 gramos de resveratrol en polvo sobre $100 \mathrm{ml}$ de DMSO, a partir de ésta se realizaron diluciones correspondientes a $10^{1}, 10^{2}, 10^{3}$ las cuales fueron pipetadas en placas de Nest $1,8 \mathrm{ml}$ de cada dilución junto con $200 \mathrm{~m}$ de cada una de ellas inoculo fúngico. Posteriormente estas muestras fueron sembradas en ágar mycosel. La misma metodología siguió en la utilización de los jugos de uva. Se percibió inhibición del crecimiento fúngico de las cinco especies probadas demostrando la actividad del resveratrol contra los aislados de Candida. Sin embargo, el tratamiento con el menor porcentaje de resveratrol utilizado en el estudio no desencadenó inhibición del crecimiento de las especies C. glabrata y C. tropicalis. En cuanto a las pruebas con jugo, dos de las tres marcas probadas tuvieron la acción similar al del resveratrol en polvo sobre las cepas de Candida. Considerando los resultados obtenidos, se puede sugerir la utilización del resveratrol como una sustancia antifúngica potencial.

Palabras clave: Polifenol, Polygonum cuspidatum, Antifúngicos, Triazoles.

\section{INTRODUÇÃO}

O resveratrol foi identificado pela primeira vez em 1940 nas raízes do heléborobranco (Veratrum grandiflorum) e posteriormente na Japanese (Polygnum capsidatum) um polifenol nominado de resveratrol (RUIVO et al. 2015) bastante utilizado na medicina tradicional chinesa e japonesa. Anos mais tarde, em 1976, o composto foi identificado principalmente na película de uvas da espécie Vitis vinifera (PAULO, 2011). Em 1992 foi 
atribuído ao resveratrol presente no vinho tinto a característica de agente cardioprotetor. Desde então, este polifenol recebeu interesse renovado, através de publicações, demonstrando que o resveratrol pode reduzir ou prevenir a progressão de diversas doenças cardiovasculares, infecções bacterianas, antifúngicas, e prolongar também a longevidade em organismos humanos (MACHADO, 2013). Na planta, o resveratrol tem a função de proteção e combate na infecção por fungos (RUIVO et al. 2015). O resveratrol atinge um pico durante o processo de formação e amadurecimento das uvas, estando associados aos fatores estressantes como, por exemplo, o clima, ambiente de cultivo, exposição a diferentes patógenos, entre outros (BARCELLOS, 2016). Ademais pode ser encontrado e quantificado em diversas famílias de plantas, destacando-se, o eucalipto (Eucalyptus wandoo, Myrtaaceae), o amendoim (Arachis hypogacea, Fabaceae), e as variedades de uvas como Merlot, Carbenet Sauvigono e Pinot Noir. O resveratrol encontra-se presente também na constituição química de diversos tipos de sucos de uva (SAUTTER, 2005). Esse antioxidante é quimicamente designado por 3, 4, 5, trihidroxiestilbeno e a combinação de duas formas isômeras presentes exibem efeito benéfico com propriedades medicinais (BARCELLOS, 2016). Outrossim, o resveratrol apresenta-se com fórmula molecular $\mathrm{C} 14 \mathrm{H} 12 \mathrm{O} 3$ e possui massa molecular de $228 \mathrm{~g} / \mathrm{mol}$, ponto de fusão entre $253^{\circ} \mathrm{C}$ e $255^{\circ} \mathrm{C}$, e pKa de 9,14 , com elevada solubilidade em solventes orgânicos e baixa solubilidade em água (SOUZA, 2009).

A ação antifúngica é uma ferramenta essencial na terapia de doenças infecciosas causadas por fungos, ainda assim, se observa um aumento relativo da resistência dos microorganismos aos fármacos convencionais (ALVES, 2015). Dentre as diversas espécies de fungos, destaca-se o gênero Candida, sendo que as espécies de maior interesse clínico são $C$. albicans, C. krusei, C. tropicalis, C. glabrata e C. parapsilosis, que são encontradas em diversas partes do corpo em indivíduos clinicamente saudáveis, mas, podem tornar-se potencialmente patogênicas, quando expostas em ambiente favorável para seu o crescimento (ÁLVARES et al. 2007; RODRIGUES et al. 2014 TOZZO et al. 2012). A C. albicans pode ser considerada um fungo dimórfico por apresentar a forma de levedura ou filamentosa, podendo ainda assumir a forma de pseudo-hifas, em que as células são alongadas e se encontram agrupadas (SANTANA et al. 2012). C. glabrata cresce apenas em forma de blastoconídios, não sendo polimórfica. No caso de C. parapsilosis, não produz hifas verdadeiras, mas apenas pseudo-hifas, e o crescimento do blastoconídios é prevalente, já em cepas de $C$. tropicalis ocorre a produção de blastoconídios ovais e pseudo-hifas (SILVA et 
al. 2011). Alterações no sistema imunológico do hospedeiro são consideradas um relevante fator de risco predisponente à aquisição da doença, e além destes fatores, o próprio fungo apresenta fatores de virulência (PLAYFORD et al. 2008).

Frente as informações expostas, considerando a carestia em estudos que conduzam esta mesma abordagem, o objetivo desse trabalho foi analisar a ação antifúngica do composto resveratrol na forma sólida e presença natural no suco integral de uva frente a diferentes espécies de Candida potencialmente patogênicas.

\section{MATERIAIS E MÉTODOS}

O trabalho foi desenvolvido no Laboratório Escola da Universidade Luterana do Brasil, da cidade de Carazinho, RS, no período de agosto a setembro de 2017.

\section{Material fúngico}

A população foi constituída por espécies C. albicans, C. glabrata, C. krusei, C. tropicalis e C. parapsilosis oriundas da Micoteca do curso de Biomedicina da ULBRA

Carazinho, tendo estas suas identificações fenotípicas prévias utilizando o equipamento Vitek, no qual nenhuma apresentou perfil de resistência aos antifúngicos usuais, como Fluconazol. As cepas foram repicadas em placas contendo meio de cultura HiCrome Candida Agar (Himedia Laboratories), e incubadas em estufa microbiológica em temperatura $37{ }^{\circ} \mathrm{C}$. Após 48 horas de incubação, observou-se o crescimento fúngico das espécies identificadas, e a partir desse crescimento foram removidas da superfície das placas cinco colônias jovens e adicionadas a $2 \mathrm{~mL}$ de solução fisiológica estéril, realizando a preparação do inóculo fúngico de acordo com os padrões da Escala 0,5 MacFarland.

\section{Delineamento do Estudo}

Analisar a ação antifúngica do resveratrol sobre cepas de diferentes espécies de Candida spp., utilizando o fármaco Fluconazol como controle, devido ser um medicamento comumente utilizado no tratamento convencional das candidíases. As concentrações seguiram exatamente a mesma proporção de teste, onde foram definidas segundo 
protocolo M27-A2 estabelecido pelo Clinical and Laboratory Standards Institute (NCCLS, 2002).

\section{Procedimento Metodológico}

\section{Preparo da solução em pó de resveratrol}

O pó de resveratrol foi obtido a partir de uma farmácia de manipulação, contendo 99\% de pureza, e foi preparado utilizando Dimetilsulfóxido (DMSO) (Neon) como solvente. Pesou-se 0,5 gramas do pó, que foi solubilizado em $100 \mathrm{~mL}$ de DMSO, e para o controle utilizou-se Fluconazol em pó, nas mesmas proporções. A concentração de inibição mínima (MIC) para resveratrol foi determinada de acordo com o protocolo M27A2 (15). Para garantia da qualidade do experimento, foi realizado controle negativo da técnica, o qual foi constituído apenas pelo diluente DMSO, e controle positivo no qual houve incubação dos inóculos com a suspensão de leveduras sem a presença dos antifúngicos.

\section{Execução do teste utilizando resveratrol em pó}

Para execução do teste de inibição de crescimento foi utilizado placa de cultura celular (Nest) apresentando volume final de $200 \mu$ l. Inicialmente, foram feitas diluições seriadas de resveratrol correspondentes a $10^{-1}, 10^{-2}$ e $10^{-3}$, e a seguir pipetou-se $1,8 \mathrm{~mL}$ de cada diluição nos poços da placa e incubados com $200 \mu$ do inóculo realizado com as suspensões dos fungos por $48 \mathrm{~h} / 35^{\circ} \mathrm{C}$. Posteriormente, uma alíquota das amostras foram semeadas em placa de Petri contendo ágar Mycosel, e incubadas em estufa microbiológica a $35^{\circ} \mathrm{C}$. As leituras foram realizadas após $24 \mathrm{~h}$ e 48 horas de crescimento.

\section{Preparo da solução de resveratrol de ocorrência natural}

Foram adquiridas no comércio de Carazinho (RS), amostras de sucos de uva integral de três marcas comerciais diferentes, produzidos na Serra Gaúcha. Para o estudo as amostras de suco foram utilizadas conforme sua apresentação comercial, como solução de teste. 


\section{Execução do teste utilizando Resveratrol de forma natural}

Para execução do teste de inibição de crescimento foi utilizado a placa de cultura celular (Nest). Inicialmente, pipetou-se $1,8 \mathrm{~mL}$ de cada amostra de suco das diferentes marcas nos poços da placa juntamente com 200 ul dos inóculos de candida preparados anteriormente. Incubou-se por $48 \mathrm{~h} / 35^{\circ} \mathrm{C}$. Após esse período, semearam-se as soluções dos poços pela técnica de gota em placas com ágar Mycosel que foram incubadas novamente em estufa microbiológica em ar atmosférico à $35^{\circ} \mathrm{C}$.

\section{Avaliação dos testes}

Decorrido 48 horas de incubação, avaliou-se o crescimento das colônias nas placas dos testes realizados com a solução do pó de resveratrol e com a solução do suco de uva. Foi realizado um controle positivo de crescimento utilizando DMSO sem resveratrol e sem fluconazol.

\section{RESULTADOS}

A análise dos resultados da avaliação das espécies de Candida spp. tratadas com resveratrol em pó indicou uma ação de inibição de crescimento fúngico diferente entre as espécies, considerando as concentrações testadas (Tabela 1). Não houve inibição na germinação do crescimento fúngico pelo resveratrol em concentrações de 0,005\% $(5 \mu \mathrm{g} / \mathrm{mL})$ e $0,0005 \%(0,5 \mu \mathrm{g} / \mathrm{mL})$ representados na tabela 1 por $10^{-2}$ e $10^{-3}$ frente as espécies de $C$. glabrata e C. tropicalis no período de 24 horas e 48 horas de incubação. Ao contrário, nas demais espécies testadas com resveratrol nessas concentrações ocorreu a inibição do crescimento dos fungos. Entretanto, o aumento da concentração de resveratrol para 0,05\% $(50 \mu \mathrm{g} / \mathrm{mL})$ representado na tabela 1 como $10^{-1}$ causou inibição completa de crescimento em todas as espécies, inclusive a C. glabrata e a C. tropicalis. A área de identificação obtida pelos testes referente aos valores encontrados frente ao resveratrol está representada na figura. 
Tabela 1 - Resultados da ação do resveratrol em pó em diferentes concentrações sobre o crescimento das diferentes espécies de Candida utilizadas.

\begin{tabular}{lcll}
\hline \multicolumn{1}{c}{ Espécies } & $\mathbf{1 0}^{-1}$ & $\mathbf{1 0}^{-2}$ & $\mathbf{1 0 - 3}$ \\
& $(\mathbf{0 , 0 5 \% )}$ & $(\mathbf{0 , 0 0 5 \% )}$ & $(\mathbf{0 , 0 0 0 5 \% )}$ \\
\hline C.glabrata & - & ++ & +++ \\
\hline C.tropicalis & - & ++ & +++ \\
\hline C.krusei & - & - & - \\
\hline C.parapsilosis & - & - & - \\
\hline C.albicans & - & - & - \\
\hline
\end{tabular}

Legenda: , + crescimento 01 colônia; ++ crescimento de 2-5 colônias;

+++ crescimento $>05$ colônia

Fonte: Cruz; Ehrhardt (2017).

A avaliação do teste utilizando o Fluconazol como controle nas mesmas concentrações do resveratrol em pó, no mesmo experimento, estão representados na Tabela 2. O Fluconazol não foi capaz de inibir o crescimento nas concentrações $(0,005 \%)$ e $(0,0005)$ representados na tabela 2 por $10^{-2}$ e $10^{-3}$ nas espécies $C$. glabrata e C. tropicalis, porém, em doses maiores 0,05\% ocorreu inibição. Não houve inibição pelo fluconazol também na espécie C. parapsilosis em nenhuma das concentrações. Já as espécies C. krusei e C. albicans não manifestaram crescimento fúngico em nenhum dos testes realizados com o fluconazol. A área de identificação obtida pelos testes referente aos valores encontrados frente ao fluconazol estão representados na figura 2.

Tabela 2 - Resultados da ação do Fluconazol em concentrações iguais ao utilizado com resveratrol, teste controle.

\begin{tabular}{llll}
\hline \multicolumn{1}{c}{ Espécies } & $\begin{array}{l}\mathbf{1 0 - 1} \\
\mathbf{( 0 , 0 5 \% )}\end{array}$ & $\begin{array}{l}\mathbf{1 0 - 2} \\
\mathbf{( 0 , 0 0 5 \% )}\end{array}$ & $\begin{array}{l}\mathbf{1 0 - 3} \\
\mathbf{( 0 , 0 0 0 5 \% )}\end{array}$ \\
\hline C.glabrata & - & ++ & ++ \\
\hline C.tropicalis & - & ++ & + \\
\hline C.krusei & - & - & ++ \\
\hline C. parapsilosis & + & + & - \\
\hline C.albicans & - & - & ++ \\
\hline $\begin{array}{l}\text { Legenda: + crescimento 01 colônia; ++ crescimento de 2-5 colônias; +++ } \\
\text { crescimento > 05 colônia }\end{array}$ & & \\
\hline \multicolumn{2}{l}{ Fonte: Cruz ; Ehrhardt (2017). }
\end{tabular}


Com a finalidade de avaliar a resposta do crescimento fúngico frente ao resveratrol também na sua forma natural, além da solução em pó, utilizando os diferentes tipos de sucos de uva integral industrializado, obteve-se resultados que estão esquematizados na tabela 3. O suco representado pela marca (A) não desenvolveu ação de inibição em nenhuma das espécies de Candida. Porém, os sucos representados pela marca (B) e marca (C) obtiveram resultados de inibição do crescimento das colônias fúngicas. Meramente na espécie $C$. tropicalis foi evidenciado o crescimento de 1 colônia fúngica.

Tabela 3 - Resultados da ação das diferentes marcas de Suco de uva testados sobre as espécies de Candida.

\begin{tabular}{lccc}
\hline \multicolumn{1}{c}{ Espécies } & Suco A & Suco B & Suco C \\
\hline C. glabrata & ++ & - & - \\
\hline C. tropicalis & +++ & + & - \\
\hline C. krusei & +++ & - & - \\
\hline C. parapsilosis & + & - & - \\
\hline C. albicans & +++ & - &
\end{tabular}

Legenda: , + crescimento 01 colônia; ++ crescimento de 2-5

colônias; +++ crescimento $>05$ colônia

Fonte: Cruz; Ehrhardt (2017)

\section{DISCUSSÃO}

No presente estudo foi avaliado o potencial de inibição do resveratrol sobre as culturas com espécies de Candida spp. As suposições testadas pelos nossos estudos apresentaram resultado satisfatório, pois, o resveratrol demonstrou ação de inibição fúngica em vários testes.

A suscetibilidade in vitro dos 5 isolados de Candida testados em nossa casuística mostrou que concentrações de 0,05\%, equivalente a $50 \mu \mathrm{g} / \mathrm{mL}$ de resveratrol proporcionaram inibição completa do crescimento fúngico.

Ainda, as concentrações menores apresentadas tiveram ação sobre três espécies ( $C$. Krusei, C. parapsilosis e C. albicans) isoladas, pois não desenvolveram crescimento fúngico frente ao resveratrol nas baixas concentrações, o qual assevera maior atividade do que fluconazol contra os isolados de Candida. Cendejas et al. (2010) verificou a resistência de diversas espécies de Candida a este antifúngico em isolados clínicos obtido no exterior, sendo que maior resistência foi verificada $\operatorname{com} C$. glabrata e C. krusei. Com relação à espécie 
de C. krusei, é um resultado de suma importância comprovando a eficácia do polifenol testado, visto que se trata de uma espécie fúngica nosocomial patógena encontrada principalmente em pacientes imunocomprometidos e com malignidades hematológicas. Ademais, também não apresentou crescimento fúngico frente ao fluconazol, um agente antifúngico padrão.

A inibição do crescimento fúngico da espécie $C$. parapsilosis frente ao resveratrol se torna importante, visto que, se trata de um fungo comensal de pele humana, e sua patogenicidade é limitada por integumento intacto, é conhecida por sua capacidade de crescer na nutrição parenteral, e formar biofilmes em cateteres e outros dispositivos implantados (SABINO et al. 2014). A disseminação nosocomial é uma preocupação especial em recém-nascidos causando infecções fúngicas invasivas em bebês de baixo peso. Além disso, é o organismo fúngico predominantemente isolado em muitas unidades de cuidados intensivos neonatais, onde frequentemente está associado à mortalidade neonatal (TROFA et al., 2008).

Como demonstrado na tabela 1 e tabela 2, ocorreu inibição total do crescimento fúngico de C. albicans em relação ao polifenol testado e o fármaco controle. Este achado é de extrema relevância posto que dentro do gênero Cândida, a levedura mais importante é a albicans, visto que é um patógeno oportunista que pode causar infecções disseminadas em grupos de pacientes específicos (PAPADOPOULOU,2005). Esta levedura faz parte da microbiota natural do ser humano e, em algum momento ela adquire a capacidade de causar doenças (COSTA, et al. 2009). Ainda podemos altear que o resveratrol pode potencializar as propriedades farmacológicas dos fármacos convencionais, como o Fluconazol, facilitando de modo geral o tratamento rápido e eficaz.

A C. albicans, se destaca principalmente em infecções nosocomiais, é o principal agente de fungemia no mundo. É uma das espécies mais isoladas, e com maior sensibilidade quando tratada com resveratrol (BADIIE, 2011). Ainda pode causar infecções nas mucosas de hospedeiros imunocomprometidos (OKAMOTO et al. 2010).

A patogenicidade causada por espécies de Candida está fortemente relacionada a altas taxas de infecções hospitalares. Em sua maioria, estas infecções evoluem para um quadro de disseminação na corrente sanguínea, podendo ocasionar a morte do paciente (KUHN et al., 2002). 
De modo semelhante, Jung Hungs et al. (2007) isolaram o resveratrol diretamente da casca da uva, e avaliaram sua ação sobre C. albicans, o qual apresentou atividade antifúngica potente com concentrações finais de MIC na faixa de $10-20 \mu \mathrm{g} / \mathrm{ml}$ contra as estirpes de fungos testadas, porém, apresentando ação menos efetiva que a anfotericina $B$ tendo valores de MIC entre 5 - $10 \mu \mathrm{g} / \mathrm{ml}$.

Segundo Carvalho et al. (2016) que compararam a ação do resveratrol sobre o crescimento e a viabilidade do biofilme da C. albicans, utilizando concentrações $5 \mathrm{uM}, 10 \mathrm{uM}$, 20 uM, 50 uM, 100uM, 200 uM, 300 uM, 400 uM e 500 uM, obtiveram como resultado inibição no crescimento somente na maior concentração, porém, o polifenol foi capaz de alterar a morfologia das células e reduzir a viabilidade do biofilme da C. albicans.

A avaliação do efeito do resveratrol em associação aos compostos organocalcogeneos obteve resultados satisfatórios sobre o crescimento de C. albicans, pois, o resveratrol foi capaz de inibir o crescimento em até 85\%, potencializando os efeitos dos compostos disseleneto de difenila ( $\mathrm{PhSe})_{2}$, methoxyl-dephenyl diselenide (MeOPhSe) ${ }_{2}$, e pCI disseleneto difenila (pCl-PhSe) ${ }_{2}$ (MACHADO, 2013).

O antifúngico considerado convencional para o tratamento das candidíases é fluconazol, devido a isso foi utilizado no presente estudo como grupo controle.

Sem embargo, consoante com os resultados da presente pesquisa, o grupo controle também não apresentou resposta de inibição no crescimento das espécies $C$. glabrata e $C$. tropicalis tratadas com doses menores. A inibição ocorreu conforme a concentração mínima indicada pela ANVISA. O Fluconazol é um agente antifúngico triazólico, com atividade sobre várias espécies de fungos. Sua ação antifúngica está relacionada com a inibição da biossíntese do ergosterol de origem fúngica, através da inibição do desmetilase, presente na membrana celular, impedindo com isto o crescimento fúngico de algumas espécies (SANTOS et al. 2005).

Wohlmeister (2015) em uma pesquisa micológica associada à citologia cérvicovaginal identificou as espécies de C. albicans, C. glabrata e C. Krusei e avaliou os seus perfis de resistência concluindo que, na maioria das espécies, cerca de 48,57\% apresentaram perfil de resistência ao Fluconazol.

Menezes et al. (2009) verificaram que três cepas de C. tropicalis de seu trabalho foram resistentes ao fluconazol e também eram resistentes ao itraconazol. 
De acordo com o resultado encontrado para C. parapsilosis testada frente ao resveratrol, não demonstrou crescimento fúngico, e quando exposta ao fluconazol desenvolveu crescimento fúngico em todas as concentrações. Cepas de C. parapsilosis podem apresentar resistência ao fluconazol porque possuem um gene ERG 11 sequenciado, o qual revela mutação em dois nucleotídeos conduzindo à substituição de um aminoácido e alteração do sequenciamento da proteína gerada (EHRHARDT, 2017).

A presença do fluconazol provoca a superexpressão do gene ERG 11, gene este relacionado a resistência ao fluconazol. Cepas de candida resistentes ao fluconazol frequentemente também eram resistentes ao voriconazol (COLOMBO et al. 2006; PINHATI, 2015).

Entretanto, Weber et al. (2009) investigou o efeito do resveratrol utilizando as mesmas espécies e mesmas concentrações testadas em nosso estudo, incluindo também a $C$. dubliniesses, todavia, não apresentou nenhuma propriedade antifúngica em todas as experiências realizadas, o crescimento fúngico persistiu até a maior concentração do polifenol. Estes achados divergem os resultados do nosso estudo visto que a metodologia aplicada é semelhante, porém, a forma de preparo da solução e diluições foi diversificada o que pode explicar a diferença nas conclusões dos estudos, onde utilizamos concentrações maiores de resveratrol, o que pode ter ocasionado a inibição fúngica.

Em consequência disso, houve a curiosidade em testar uma metodologia adicional, empregando o resveratrol na sua forma natural, utilizando sucos de uva integral comercial.

Visto que o resveratrol apresenta-se sob duas formas isômeras cis-resveratrol e trans resveratrol, estas formas podem conter o mesmo tipo e número de átomos, mas a orientação dos átomos é ligeiramente diferente (MORENO, 2008). O trans-resveratrol está disponível comercialmente em sucos e alimentos e tem sido objeto de mais investigação do que cis-resveratrol. Portanto, para somar os resultados do presente estudo, incluíram-se também os testes utilizando sucos de uva comercial.

Destarte, em tratar-se de uma pesquisa de caráter experimental sobre a inibição do crescimento fúngico, com objetivo em comprovar ainda mais a eficácia do polifenol sobre a inibição do crescimento das candidas, explica-se que não houve a necessidade em utilizar mais que três marcas de sucos comerciais diferentes, porém, todos são de modalidade integral por conter a uva integralmente, com casca e semente, e produzidos na Serra 
Gaúcha. A escolha do suco se designou pelo fato de encontrar-se mais acessível ao consumo da população, podendo futuramente ser um aliado para prevenção e tratamento de candidas patogênicas, principalmente as bucais.

Os sucos utilizados são elaborados por cortes de uvas americanas das variedades, Isabel Bodô, Seibel e Concord, na quantidade de $1 \mathrm{~kg}$ de uva para $750 \mathrm{ml}$ de suco e são compostos por conservante INS 202 (sorbato de potássio) e conservante INS 220 (dióxido de enxofre), com pH 3,25. Esses conservantes podem ser capazes de inibir a proliferação fúngica e bacteriana (MAIA et al. 2005).

O sorbato de potassio é um conservante que possui poder fungistático, porém, sua ação depende do número de células de leveduras. Além disso, as bactérias lácticas podem degradar o Sorbato de potássio, devido a isso, é recomendado utilizá-lo na presença de um teor suficientemente elevado de dióxido de enxofre, e mesmo assim pode diminuir sua estabilidade (RIZZON et al. 1998).

O dióxido de enxofre é um conservante que deve ser aplicado logo após o esmagamento da uva, pois, se designa em impedir o processo de fermentação e pode desencadear a ação de inibição das leveduras. Porém, essas propriedades do dióxido de enxofre devem desaparecer com o processo de dessulfitação (RIZZON et al. 1998).

Por conseguinte, podemos sugerir que os resultados obtidos de inibição estão mais suscetíveis a serem provenientes da ação do resveratrol e não dos conservantes presentes no suco.

Assentido com os achados atingidos, das três marcas testadas, somente a marca A não apresentou inibição do crescimento das colônias fúngicas em nenhuma das espécies de Candida testadas. Tal fato pode ser explicado pela influência de possíveis diferenças de processamento (tempo de extração, tratamento térmico, armazenamento, variedade da uva etc) (MALACRIDA, 2005).

Contrapartida, as outras duas marcas de sucos B e C expressaram a ação de inibição frente ao crescimento fúngico das espécies testadas. Os resultados de inibição são semelhantes aos testes com resveratrol em pó, isso pode ser explicado a ação do polifenol presente na uva, visto que a composição do suco não apresenta outro componente, além dos conservantes. 
Adrian et al. (2000) comparou o nível de resveratrol e seus derivados em três variedades de uva. A concentração destes compostos foi avaliada, e observaram que o resveratrol é um componente com atividade antifúngica na espécie de uva Vitis vinifera.

A sensibilidade ao resveratrol verificada em nosso trabalho pode ser devidamente explicada justificando que o polifenol possui propriedades semelhantes aos antifúngicos convencionais atuando na parede celular fúngica, sendo capaz de interferir na ação de proteínas que estão intimamente relacionadas com o ciclo celular humano.

\section{CONCLUSÃO}

No presente estudo, evidenciou-se que a inibição total do crescimento fúngico das cinco espécies testadas ocorreu na maior concentração utilizada de resveratrol contra os isolados de Candida.

Assim sendo, sugere-se que o polifenol testado possui características convenientes para desenvolvimento de novas drogas antifúngicas ou também ser utilizado para potencializar o efeito dos antifúngicos usuais, visto que a disseminação das infecções fúngicas vem suscitando um aumento significativo nos últimos anos.

\section{REFERÊNCIAS BIBLIOGRÁFICAS}

ADRIAN M, Jeandet P, Douillet-Breuil AC, Tesson L, Bessis R 2000. Stilbene content of mature Vitis vinifera berries in response to UV-C elicitation. J Agric Food Chem 48: 6103-6105.

ÁLVARES, Cassiana A.; SVIDZINSKI, Terezinha I. E.; CONSOLARO, Márcia E. L. Candidíase vulvovaginal: fatores predisponentes do hospedeiro e virulência das leveduras. Jornal Brasileiro de Patologia e Medicina Laboratorial, v. 43 (5) p. 319 - 327. 2007

ALVES, Andreia Catarina Lopes et al. O resveratrol como uma molécula anti-envelhecimento. Dissertação Mestrado Integrado em Ciências Farmacêuticas. Universidade Lusófona de Humanidades e Tecnologias Faculdade de Ciências e Tecnologias da Saúde. Lisboa, 2015.

BADIEE P, Alborzi A. Susceptibility of clinical Candida species isolates to antifungal agents by E-test, Southern Iran: a five year study. Iran J Microbiol. 2011 Dec;3(4):183-8.

BAUER J. A. e Sinclair D. A., "Therapeutic potential of resveratrol: The in vivo evidence," Nat. Rev. Drug Discov., vol. 5, pp. 493-506, 2006

BARCELLOS,E .C. S. Avaliação do Potencial Terapeutico do Resveratrol , com uma nova droga contra Leishmaniose Viceral. Universidade Federal do Espírito Santo Programa de pós-graduação biotecnologia. 
CARVALHO, M. L. et al. Efeito antifúngico do resveratrol sobre a candida albicans . Universidade do Vale do Paraíba, Laboratório de Bioquímica aplicada a Engenharia Biomédica. São Jose dos Campos. São Paulo, 2016.

CENDEJAS, B ; GOMES, L A, Mellado E, Rodriguez-Tudela JL, Cuenca-Estrela M 2010. Identification of pathogenic rare yeast species in clinical samples: comparison between phenotypical and molecular methods. J Clin Microbiol 48: 1895-1899.

COLOMBO AL, Nucci M, Park BJ, Nouér SA, Arthington-Skaggs B, Matta DA, et al. Epidemiology of candidemia in Brazil: a nationwide sentinel surveillance of candidemia in eleven medical centers. J Clin Microbiol. 2006 Aug;44(8):2816-23.

COSTA, C. R. et al. Fatores de virulência de isolados de candida de pacientes imunocomprometidos. caracterização molecular de candida albicans suscetíveis e resistentes ao Fluconazol. Universidade Federal de Goiás Instituto de Patologia Tropical e Saúde Pública. 2009.

EHRHARDT, Alexandre. Cimento de ionômero de vidro modificado com sal imidazólico biomaterial funcionalizado com propriedades antibiofilme fúngico.Dissertação de Mestrado;Universidade Federal do Rio Grande do Sul. Instituto de Ciências Básicas da Saúde. Programa de Pós-Graduação em Ciências Biológicas: Farmacologia e Terapêutica. Porto Alegre, 2017.

JUNG, HJ, KS Choi,;DG Lee. 2007. Synergistic matando efeito do péptido sintético P20 e cefotaxima sobre nosocomiais isolados resistentes à meticilina de Staphylococcus aureus. J. Microbiol. Biotechnol. 15: 10391046.

KUHN, D. M.; CHANDRA, J.; MUKHERJEE, P. K.; GHANNOUM M. A. Comparison of biofilms formed by Candida albicans and Candida parapsilosis on bioprosthetic surfaces. Infect. Immun., 70(2), 878- 88, 2002

MACHADO, Cecília Ferreira. Efeito do Resveratrol em associação com compostos organacalcogêneos (PhSe) 2,(MeOPhSe) 2,(p-Cl-PhSe) 2 em Candida albicans. Universidade do Vale do Paraíba Instituto de Pesquisa e Desenvolvimento Faculdade de Educação e Artes - Ciências biológicas. São Paulo (2013).

MAIA, JD \& Camargo UA. Sistema de Produção de Uvas Rústicas para Processamento em Regiões Tropicais do Brasil. Embrapa Uva e Vinho, Sistema de Produção.2005

MALACRIDA, C.R.; MOTTA, S. Compostos fenólicos totais e antocianinas em suco de uva. Universidade Federal de Minas Gerais - Departamento de Alimentos, Faculdade de Fármacia, Campinas, v. 25, p. 659-664, 2005.

MENEZES, Everardo Albuquerque; MENDES, Luana Guabiraba; CUNHA, Francisco Afrânio. Resistência a antifúngicos de Candida tropicalis isoladas no Estado do Ceará.Rev. Soc. Bras. Med. Trop., Uberaba, v. 42, n. 3, p. 354-355, June 2009

MORENO, A.; CASTRO, M.; FALQUE, E. - Evolution of trans- and cis-resveratrol content in red grapes (Vitis vinifera L. cv Mencia, Albarello and Merenzao) during ripening. European Food Research and Technology.

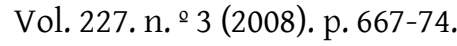

NCCLS. Método de Referência para Testes de Diluição em Caldo para a Determinação da Sensibilidade a Terapia Antifúngica das Leveduras; Norma Aprovada-Segunda Edição. Norma M27-A2 do NCCLS (ISBN 156238-469-4). NCCLS, 940 West Valley Road, Suite 1400, Wayne, Pennsylvania 19087-1898 Estados Unidos, 2002

OKAMOTO-SHIBAYAMA, Kazuko; SATO, Yutaka; AZUMA, Toshifumi. Resveratrol impaired the morphological transition of Candida albicans under various hyphae-inducing conditions. J. Microbiol. Biotechnol, v. 20, n. 5, p. 942-945, 2010.

PAPADOPOULOU, Chrissanthy; SOULTI, Kalliopi; ROUSSIS, Ioannis G. Potential antimicrobial activity of red and white wine phenolic extracts against strains of Staphylococcus aureus, Escherichia coli and Candida albicans. Food Technology and Biotechnology, v. 43, n. 1, p. 41-46, 2005. 
PAULO, L. A. S. Determinação dos teores de resveratrol em vinhos tintos com denominação de origem controlada Beira Interior e avaliação das suas propriedades antimicrobianas.Dissertação de Mestrado. Universidade da Beira Interior Ciências da Saúde 2011.

PINHATI, Henrique Marconi Sampaio. Surto de candidemia por candida parapsilosis resistente ao fluconazol, em um hospital em Brasília: Caracterização clínica, molecular e avaliação dos fatores associados. 2015. 107 f., il. Tese Doutorado em Ciências Médicas Universidade de Brasília, Brasília, 2015.

PLAYFORD, E. Geoffrey et al. Candidemia in nonneutropenic critically ill patients: risk factors for non-albicans Candida spp. Critical care medicine, v. 36, n. 7, p. 2034-2039, 2008.

RIZZON, L.A.; MANFROI, V., MENEGUZZO, J.; Elaboração de suco de uva na propriedade vitícola, Bento Gonçalves: Embrapa Uva e Vinho, 1998. 24p.

RODRIGUES, Giselda P. S. et al. Ação de extratos vegetais hidroalcoólicos sobre Cândida sp. Revista CuidArte Enfermagem, v. 8 (1) p. 32-39. 2014.

RUIVO, Joana; FRANCISCO, Cátia; OLIVEIRA, Rita and FIGUEIRAS, Ana. The main potentialities of resveratrol for drug delivery systems. Braz. J. Pharm. Sci.. 2015, vol.51, n.3 2017 pp.499-513.

SABINO, Raquel et al. Genotipagem de Candida parapsilosis com marcadores de DNA microssatélite: uma ferramenta para o estudo e controlo das infeções hospitalares. Boletim Epidemiológico Observações, v. 3, p. 30-33, 2014.

SAUTTER, C. K. Avaliação da presença de Resveratrol em suco de uva. 2003. 135 f. Dissertação Mestrado em Ciência e Tecnologia de Alimentos. Universidade Federal de Santa Maria, 2005.

SANTANA, D. P. et al. Ação de chalconas contra a formação de biofilme de Candida albicans. Revista de Ciências Farmacêuticas Básica e Aplicada, v. 36, n. 1, p. 83-90, 2012.

SANTOS, JR et al. Caracteristicas gerais da ação do tratamento e da resistência fúngica ao Fluconazol. Scientia Médica. Porto Alegre, 2005

SILVA, S. et al. Adherence and biofilm formation of non-Candida albicans Candida species. Trends in Microbiology, v. 19, n. 5, p. 241-247, 2011

SOUZA, Izabel Cristina Custodio. Efeitos do resveratrol sobre as células estreladas hepáticas. Universidade Federal do Rio Grande do Sul Instituto de Ciências básicas da saúde Programa de pós-graduação em ciências biológicas. Porto Alegre, 2009.

TROFA D, Gácser A, Nosanchuk JD. 2008. Candida parapsilosis, an emerging fungal pathogen. Clin Microbiol Rev. 2008;21:606-25

TOZZO, Aline. B.; GRAZZIOTIN, Neiva. A. Candidíase Vulvovaginal. Revista Perspectiva, v. 36 (133) p. 53 - 62. Universidade Regional Integrada do Alto Uruguai e Missões. 2012.

WEBER, K.; SCHULZ, B.; RUHNKE, M. - Resveratrol and its antifungal activity against Candida species. Mycoses. (2009)

WOHLMEISTER, Denise. Avaliação da relação entre a infecção pelo Papilomavírus Humano e outros agentes sexualmente transmissíveis e a expressão de S100A4 em amostras cervicais. Dissertação de Mestrado. Universidade Federal do Rio Grande do Sul. Faculdade de Fármacia. Porto Alegre 2015.

(c)) EY

Este trabalho está licenciado com uma Licença Creative Commons - Atribuição 4.0 Internacional. 